\title{
OTIMIZAÇÃO DE RECURSOS DE EMBALAGEM PARA REDUÇÃO DO CUSTO LOGÍSTICO
}

\author{
L.H.M. Oliveira ${ }^{1}{ }^{*} ;$ R.S. Junior ${ }^{1}$; M.V. Nascimento ${ }^{1}$; R.F. Santos ${ }^{1}$ \\ 1 Faculdade de Tecnologia de São José dos Campos - Professor Jessen Vidal \\ Av. Cesare Mansueto Giulio Lattes, 1350 - Eugênio de Melo, São José dos Campos/SP, \\ CEP: 12247-014, Brasil. Telefone: (12) 3905-2423 \\ *lhmo12@yahoo.com.br
}

\begin{abstract}
RESUMO: O presente artigo tem como tema o estudo dos processos logísticos de uma empresa do setor aeronáutico, com foco na melhoria do gerenciamento dos recursos de embalagens utilizados. O processo em questão é voltado para a logística internacional, onde ocorrem processos de exportação e importação entre unidades de uma mesma empresa. Diante desse contexto, o objetivo deste artigo é identificar um modelo de embalagem mais adequado ao processo. Atualmente a empresa utiliza um modelo que não é reutilizável confeccionado em madeira. Esse modelo de embalagem requer tratamento específico e descarte no destino, o que eleva os custos despendidos no processo. O artigo avalia, com uso de análise SWOT, os problemas intrínsecos que impactam diretamente no processo em estudo, que resultam na elevação dos custos logístico afetando a competitividade da empresa.
\end{abstract}

PALAVRAS-CHAVE: Logística; embalagens; custos.

ABSTRACT: This current paper discusses the study of logistics processes of a company in the aeronautic sector and the improvement management of the packaging resources used by the company. The process is focused in international logistics, where export and import processes are done between sites of the same company. The goal in this article is to identify a packaging model most suitable for the process. Currently the company uses a wood packaging which is not reusable. This kind of packaging requires specific treatment and disposal at the destination, which increases the costs incurred in the process. Using SWOT analysis, the article evaluates the intrinsic problems that directly impact the process in study, which results in the increase of logistics costs affecting the competitiveness of the company.

KEYWORDS: Logistics; packaging; costs.

\section{INTRODUÇÃO}

Com o aumento da competitividade no cenário global as empresas buscam cada vez mais serem eficientes em seus processos logísticos com o objetivo de atender as demandas e ampliar sua participação no mercado através de bons resultados. Segundo Christopher (2011), a posição de superioridade duradoura sobre concorrentes em termos de preferência do cliente pode ser alcançada por meio de uma melhor gestão logística da cadeia de suprimentos.

Os custos absolutos logísticos de um modo geral aumentam com o crescimento da economia. Se o número de bens e serviços produzidos e consumidos aumentar, verifica-se na grande maioria das empresas um aumento do custo total relacionado com as atividades logísticas (COYLE, BARDI e LANGLEY, 2003). 
Portanto, uma boa gestão da cadeia de suprimentos é essencial, e tem como objetivo tornar a empresa mais competitiva, reduzindo custos e abrangendo todos processos desde a matéria prima até o cliente final. A logística evoluiu muito e na atualidade é uma grande geradora de vantagem competitiva, através dela pode-se também otimizar os recursos e aumentar a qualidade dos serviços prestados (BALLOU, 2010).

Segundo Moura e Banzato (1997), os gastos com embalagem representam aproximadamente $2 \%$ do PNB (Produto Nacional Bruto), e o Brasil perde entre 10\% a 15\% da sua receita de exportação por causa de embalagens deficientes. Os processos de manuseio e movimentação dos produtos, transporte e armazenamento são favorecidos por meio da padronização, pois reduz o tempo das operações e custos desnecessários.

Sendo assim, um controle de qualidade rigoroso das embalagens é necessário para que seja possível aumentar a vantagem competitiva frente a concorrência. Na padronização de cargas embaladas para fins de movimentação, a sequência recomendada é primeiro padronizar o dispositivo de acondicionamento e depois a embalagem individual (MOURA e BANZATO, 1997).

A importância da reutilização de recursos como a embalagem é a redução de custos e maior rapidez nos processos. O reaproveitamento de materiais e a economia com embalagens retornáveis têm trazido ganhos que estimulam cada vez mais iniciativas e esforços para implantação desse tipo de processo, visando à eficiente recuperação de produtos (ROGERS e TIBBEN-LEMBKE, 1998).

A finalidade é atender as necessidades dos clientes e ao mesmo tempo obter a preferência dos mesmos em relação à concorrência, para isso as empresas buscam integrar fluxos, produtos, informações, fornecedores, clientes e a organização como um todo, através de um processo de planejamento de sua cadeia de suprimentos, de forma a atender com eficiência cada vez maior e proporcionar custo-benefício a todos envolvidos (BALLOU, 2010).

\subsection{Objetivo do Trabalho}

O objetivo geral deste trabalho é identificar oportunidades para reduzir os custos com as embalagens utilizadas nos processos de exportação e importação feitos entre duas unidades de uma mesma empresa do setor aeronáutico.

Para a construção deste trabalho foram elaborados os seguintes objetivos específicos:

- Realizar pesquisa bibliográfica do conteúdo relacionado ao tema do trabalho;

- Levantar dados da empresa em estudo para análise dos resultados;

- $\quad$ Aplicação da análise SWOT para verificação de atributos relevantes para o processo logístico das embalagens na empresa em estudo.

\subsection{Proposta Metodológica}

Para atingir os objetivos deste trabalho, a metodologia utilizada foi uma pesquisa desenvolvida sobre quatro pilares: natureza, abordagem, objetivos e procedimentos técnicos conforme Figura 1.

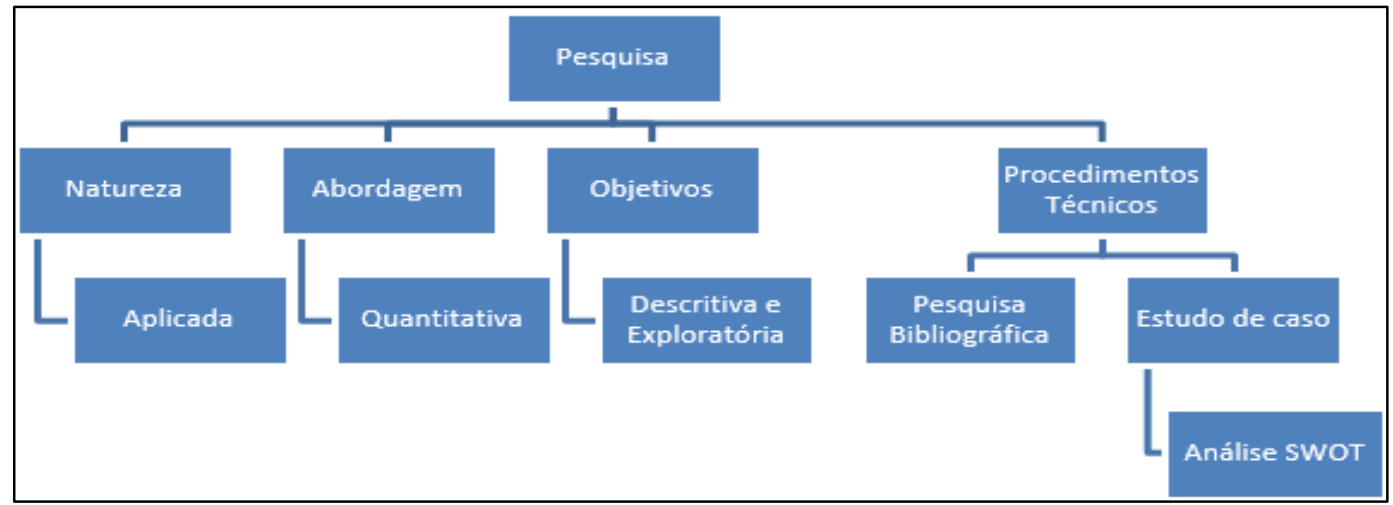

Figura 1: Proposta metodológica - Fonte: Adaptada de Santos (2010). 


\section{REVISÃO DA LITERATURA}

\subsection{Embalagem}

Embalagens são invólucros, recipientes ou qualquer forma de acondicionamento removível, ou não, destinadas a cobrir, empacotar, envasar, proteger, manter os produtos e facilitar a movimentação. Ela é essencial para a proteção dos produtos durante a sua etapa de distribuição, armazenamento, comercialização e manuseio (GURGEL, 2007).

Conforme Moura e Banzato (1997), as embalagens podem ter quatro classificações quanto a:

a) Função: primária, secundária, terciária, quaternária e de quinto nível;

b) Finalidade: de consumo, expositora, de distribuição física, de transporte e exportação, industrial ou de movimentação e de armazenagem;

c) Forma de movimentação: manual e mecânica;

d) Utilidade: retornável e não retornável.

De acordo com Gurgel (2007), as embalagens podem ser classificadas em quatro categorias:

a) Embalagens de contenção: Embalagem que tem contato direto com o produto e por isso é necessário haver compatibilidade entre os componentes do produto, da embalagem e da atmosfera existente dentro dela. Podem ser também de apresentação, contendo rótulo ou impressão.

b) Embalagens de apresentação: Embalagem que envolve a embalagem de contenção, através dela o produto é apresentado ao consumidor no ponto-de-venda. Geralmente contém uma decoração chamativa e expressiva.

c) Embalagens de comercialização: Embalagem que contém um múltiplo da embalagem de apresentação, forma a unidade para a distribuição e, é um submúltiplo da embalagem de movimentação.

d) Embalagens de movimentação: Trata-se de um múltiplo da embalagem de comercialização, pode ser movimentada racionalmente por equipamentos mecânicos.

Em torno de $40 \%$ de todas as embalagens são derivadas da madeira transformada em celulose e, consequentemente em papel e papelão, sendo que a própria madeira também é utilizada. As embalagens plásticas produzidas com base no petróleo representam cerca de $30 \%$ do total. As indústrias produtoras de embalagens as produzem com base em diversos tipos de matéria-prima e para várias aplicações (MESTRINER, 2007).

A embalagem é um componente essencial para processos logísticos, estabelecendo a base para um sistema integrado de movimentação, armazenagem e transporte. Muito importante na logística internacional, a embalagem se tornou fundamental para o sucesso dos processos de importação e exportação (MOURA E BANZATO, 1997).

Segundo Gurgel (2007), é possível devolver uma embalagem apropriada para determinada operação, com isso, diminuir a quantidade de tempo gasto e possíveis dificuldades nos processos logísticos. Adotando o critério da eliminação de custos parasitas, ao obtermos a redução de custos com a utilização de uma embalagem adequada a empresa se torna mais competitiva diante seus concorrentes.

As empresas fornecedoras de embalagens não devem ser tratadas apenas como fornecedores, mas sim como parceiros estratégicos. Conhecer esses parceiros, suas fabricas e os recursos que possuem é essencial, pois não deve ser observado apenas a qualidade e capacidade de fornecimento, mas também a competência que esses fornecedores têm de participar do desenvolvimento de novas alternativas de embalagem, a fim de obter algum tipo de vantagem competitiva (MESTRINER, 2007).

\subsection{Logística Reversa}

A crescente preocupação com o meio ambiente tem despertado a atenção da comunidade referente à utilização racional dos recursos ambientais, visando a preocupação mundial com a 
exploração dos recursos naturais e a destinação do lixo produzido pela população. Dito isso, o destino das embalagens utilizadas nas atividades logísticas trata-se de um fator de grande relevância em relação aos impactos ambientais e precisa ser analisado com cautela, visto que, as atividades logísticas vêm crescendo no decorrer dos anos e a tendência é um aumento constante conforme os países forem se desenvolvendo (NOVAES, 2009).

Para Paoleschi (2009), a logística reversa é a área que trata dos aspectos de retorno de produtos, embalagens ou materiais ao seu centro produtivo. Embora seja um tema atual, se trata de um processo que já era observado nas indústrias de bebidas com a reutilização dos vasilhames, ou seja, o produto chegava ao consumidor e após o consumo a embalagem retornava ao centro produtivo para que fosse reutilizada e novamente colocada à disposição do mesmo.

Conforme Tadeu (2013), o canal de distribuição reverso é constituído por atividades de fluxo direto, que incluem o retorno, reuso, reciclagem e a destinação correta de seus produtos e materiais constituintes. Para ele os bens de pós-consumo têm uma classificação estabelecida quanto ao tempo de vida útil, que podem ser definidos em três categorias: os produtos duráveis, os semiduráveis e os descartáveis.

As quantidades de bens pós-consumo aumentam em grandes proporções e esgotam as alternativas usuais de destinação final, desta forma, é necessário se estabelecer um equilíbrio, com o retorno de maiores quantidades de produtos e materiais de pós-consumo. Os canais de distribuição ganham destaque, uma vez que, nos processos logísticos, a distribuição representa a última etapa para disponibilizar o produto no mercado e futuramente possibilitar o seu retorno (LEITE, 2009).

Segundo Pedroso e Zwicker (2007), a logística reversa tem influência nos três elementos da sustentabilidade: econômica, social e ambiental. A econômica tem relação aos ganhos financeiros atingidos com a utilização da logística reversa. Na esfera social está relacionada aos benefícios obtidos pela sociedade com as atividades relativas a logística reversa. E por fim, o ambiental, no que se refere a redução dos impactos ao meio ambiente.

\subsection{Redução de Custos Logísticos}

Segundo Faria e Costa (2010), a logística é essencial para o sucesso de uma empresa, pois é uma área estratégica para o alcance e sustentação de vantagens competitivas, tanto pela possibilidade de proporcionar melhor nível de serviço ao cliente, quanto pela possível redução de custos logísticos e consequentemente o aumento da rentabilidade.

Os custos absolutos logísticos de uma maneira geral aumentam com o crescimento da economia. Se o volume de bens e serviços produzidos aumentar, nota-se na grande maioria das empresas um aumento do custo total relacionado com as atividades logísticas (COYLE, BARDI e LANGLEY, 2003).

No processo de redução de custos é fundamental analisar quais podem ser reduzidos ou eliminados sem que afetem de forma negativa a eficiência e a qualidade dos produtos e serviços. A busca por melhores resultados nas organizações é o principal objetivo deste trabalho, onde o lucro é igual a diferença entre o preço e o custo do produto ofertado. Como o preço é determinado pelo mercado, a saída é trabalhar os custos despendidos nos processos (BORNIA, 2001).

Os custos logísticos brasileiros são maiores que os europeus, as variações ocorrem principalmente nos custos de transporte. A diferença geográfica tem influência em alguns aspectos, mas o que é mais relevante são as inovações em recursos e processos que ainda são pouco aplicadas no Brasil. Por essa razão, fica evidente a necessidade de aprimorar a gestão de custos, para que as empresas possam ter visibilidade de cada um dos componentes do referido custo, bem como a verificação do custo logístico total. (FARIA e COSTA, 2010).

Conforme Dias (1993), uma correta administração da logística resulta em melhor aproveitamento dos recursos e dos meios de movimentação disponíveis, podendo evitar rejeições de 


\section{ISSN $2447-5378$}

produtos, reduzindo perdas no manuseio e impedindo outros extravios, fatores que tem ação direta na redução dos custos.

\section{APRESENTAÇÃO DO FERRAMENTAL DE ANÁLISE}

No planejamento estratégico de uma empresa a análise dos cenários é de extrema importância para perpetuidade da organização. A SWOT (Strengths, Weaknesses, Oppotunities e Threats) que significa forças e fraquezas, oportunidades e ameaças, é uma ferramenta muito útil para realizar análises de cenário e com isso gerenciar os elos frágeis da empresa para sua melhoria de desempenho no mercado atual (APARECIDA at al., 2015).

De acordo com Chiavenato (2000), o que pode ser controlado e analisado pela gerência está relacionado ao ambiente interno da empresa, na qual inclui os recursos do estabelecimento, sejam eles humanitários ou não. E também outro fator que pode ser avaliado são bens que não estão sendo utilizados ou o que a empresa ainda não possui mas poderá investir futuramente.

Para avaliar o ambiente externo é necessário ter uma abrangência global, pois isto apenas é monitorado e não pode ser ponderado. Este tipo de análise envolve ambientes de política, cultura e oscilações de mercado onde há tendências. Para se ter uma acurácia considerável é preciso observar seus concorrentes e assim obter uma relação em que nível de atuação eles estão e assim concluir se a tua empresa oferece uma ameaça ou está diante dela (CHIAVENATO, 2000).

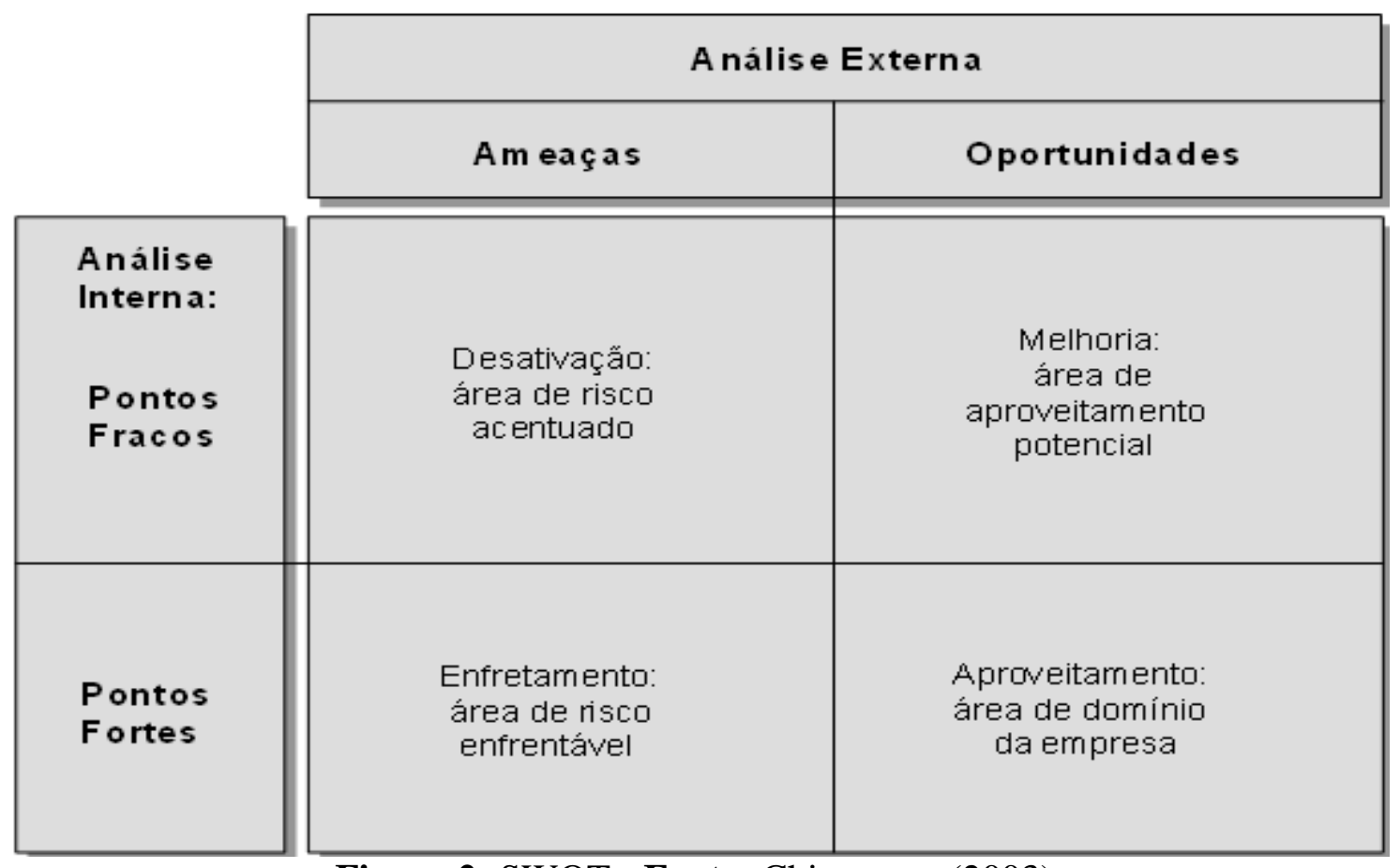

Figura 2: SWOT - Fonte: Chiavenato (2003).

Segundo Pinho (2004) para uma análise estratégica são abordados quatro pontos ideais, seguem suas definições abaixo:

a) Pontos Fortes: São fatores internos e manipuláveis que se obtém uma boa condição para a corporação, vinculando o seu ambiente.

b) Pontos fracos: São fatores internos e manipuláveis que ocasionam situações desvantajosas para a corporação, vinculando o seu ambiente. 
c) Oportunidades: São fatores externos e não manipuláveis pela empresa, isto pode formar boas situações para a corporação, mas a mesma deve ter empenho e condições para desfrutar.

d) Ameaças: São fatores externos e não manipuláveis pela corporação que são capazes de produzir situações desvantajosas para a empresa.

\subsection{Aplicação do ferramental de análise}

No primeiro quadrante apresenta as forças do cenário abrangendo o uso de embalagens de madeira para diversos tipos tamanho de produtos, no segundo quadrante é apresentada as fraquezas da utilização do mesmo. No terceiro e quarto quadrante é mostrado as oportunidades do cenário atual e por fim as ameaças são apontadas no cenário em tela.

FORÇAS
Controle de compra de embalagens
baseado na demanda.
Caixas customizadas por tamanho do
produto.
Senso de urgência para atender o prazo do
cliente em diferentes modais.
Baixo nível de refugo de produtos nas
caixas de madeira.

\section{OPORTUNIDADES}

Desenvolvimento tecnológico e inovação na construção de embalagens

Conscientização das questões ambientais na logística

Novas regulamentações da ANVISA.

Alterações do mercado.

FRAQUEZAS
Custo com o tratamento da madeira.
Atraso de embarque por dependência do
fornecedor de embalagem.
Morosidade e homem hora adicional para o
fechamento do produto dentro da caixa de
madeira.
Determinar o espaço necessário para o
estoque de caixas devido à sazonalidade de
recebimento.

\section{AMEAÇAS}

Constantes mudanças na legislação como a proibição de tratamento via brometo de metila por HT (ar quente forçado).

Indisponibilidade de matéria prima para fornecer no prazo.

Perda de contrato.

Concorrência com melhores alternativas logísticas.

Figura 3: Análise SWOT - Fonte: Adaptado dos Autores (2019).

Segundo Matos e Almeida (2007) apud Siqueira e Nascimento (2016 p. 2-3) o ferramental de análise apresenta:

"A fim de avaliar quantitativamente os resultados da aplicação do ferramental de análise SWOT aplicado ao cenário em estudo, foi aplicado ao caso em tela o construto de avaliação de cenários proposto por Matos e Almeida (2007). A metodologia sugere uma análise dinâmica baseado em quatro conceitos estratégicos:

a) Primeiro Quadrante: Potencialidade de ataque - corresponde à somatória das forças e das oportunidades;

b) Segundo Quadrante: Defensibilidade - corresponde à somatória das forças e ameaças;

c) Terceiro Quadrante: Defensibilidade de ataque - corresponde à somatória das fraquezas e oportunidades;

d) Quarto Quadrante: Vulnerabilidade - corresponde à somatória das fraquezas e ameaças. A partir da definição desses conceitos, são estabelecidas as capacidades estratégicas dos sistemas:

a) Capacidade Ofensiva - corresponde a diferença entre o potencial de ataque menos a defensibilidade de ataque; ou seja; (Forças e Oportunidades - Fraquezas e Oportunidades); 
b) Capacidade Defensiva - corresponde a diferença entre defensibilidade menos vulnerabilidade; ou seja, (Forças e Ameaças - Fraquezas e Ameaças).

Uma vez definidas as capacidades, a elaboração do construto de análise de cenários permite determinar uma avaliação quantitativa para o Posicionamento Global ou Posicionamento Estratégico. O Posicionamento Global ou Posicionamento Estratégico corresponde a diferença entre a Capacidade Ofensiva e Capacidade Defensiva; ou seja, (Capacidade Ofensiva - Capacidade Defensiva);

Matos, Matos e Almeida (2007) sugerem uma escala de valores que permite quantificar as relações e avaliar os resultados do construto proposto. A fim de implementar se a análise deve ser construída uma matriz onde as linhas apresentem os componentes internos (forças e ameaças) e as colunas apresentes os componentes externos (oportunidades e ameaças). Os indicadores de correlação entre linha e colunas são pré-definidos como:

- $\quad$ Sem Influência = correlação marcada com o valor 0 (zero)

- $\quad$ Pouca Influência = correlação marcada com o valor 1 (um)

- $\quad$ Muita Influência = correlação marcada com o valor 2 (dois)"

\subsection{Apresentação dos Resultados}

Por meio do modelo da análise SWOT foram denominados os pontos fortes e fracos, as oportunidades e ameaças na aplicação de um modelo de embalagem. As ponderações de 0 a 2 foram estabelecidas com apoio de um profissional responsável e supervisor pelo setor de logística da empresa em estudo e um especialista formado na área conforme a figura 4 a seguir:

Tabela 1: Matriz SWOT

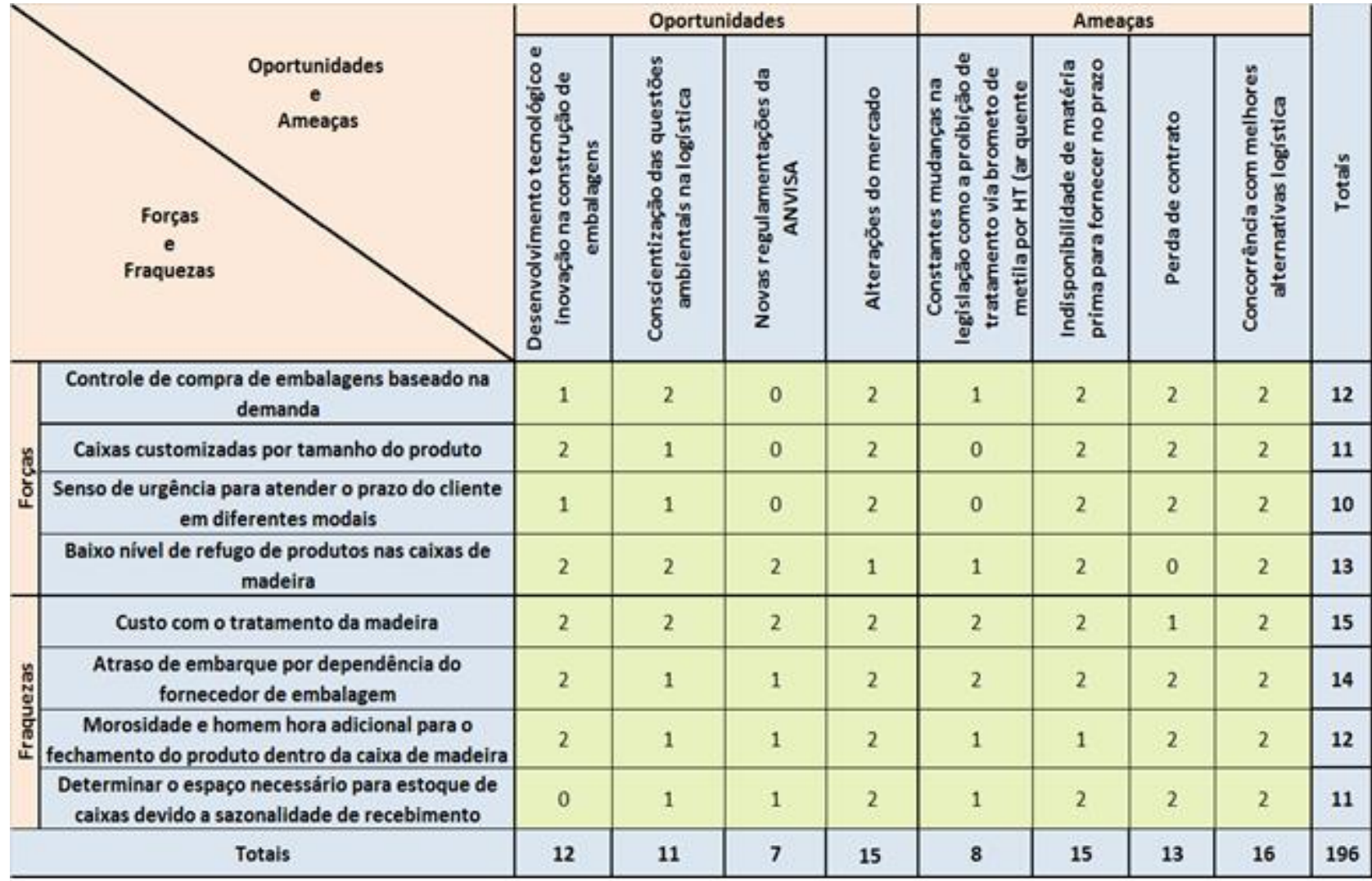

Fonte: Adaptado de Matos, Matos e Almeida (2007).

\subsection{Indicadores de impacto}


O indicador de impacto SWOT (I.I) é arquitetado a partir das respostas obtidos na soma do grau de influência da Matriz SWOT. Além do somatório de todos os itens, é realizado a multiplicação de cada ponto. O valor de cada coluna (oportunidade/ameaças) é multiplicado por cada linha (força e fraqueza) (SANTOS, 2010).

Para esse fim, o Indicador de Impacto SWOT foi dividido em três grupos a contar de uma adaptação de Santos (2010) como mostra a figura a seguir: é sugerido que os seguintes indicadores na linha e coluna totais sejam multiplicados, deste modo gerando o grau de impacto da figura 5 a seguir:

Tabela 2: Esquema de impactos para o indicador de impacto SWOT

\begin{tabular}{|c|c|c|}
\hline PONTOS & CORES & NÍVEL DE IMPACTO NA GESTÃO \\
\hline II - SWOT $>=183$ & VERMELHO & ALTO \\
II - SWOT $>=126$ ou $<183$ & AMARELO & MÉDIO \\
II - SWOT $<126$ & VERDE & BAIXO \\
\hline
\end{tabular}

Fonte: Adaptado de Santos (2010).

Em seguida será apresentado na figura 6 o Indicador de Impacto SWOT demostrando a classificação final de cada ponto:

Tabela 3: Indicador de Impactos da SWOT

Fonte: Adaptado de Santos (2010).

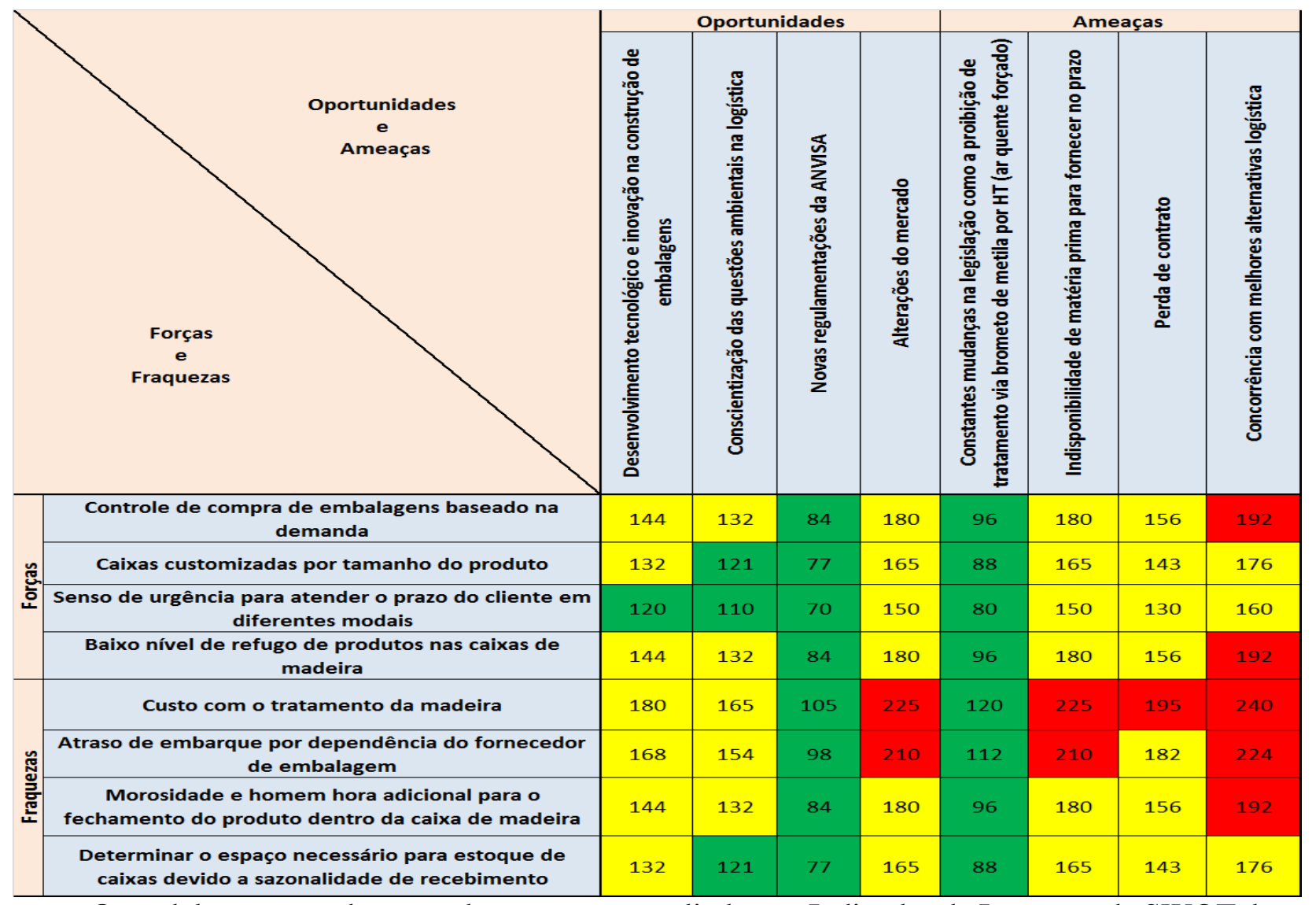

O modelo recomenda que todos os pontos avaliados no Indicador de Impactos da SWOT devem ser trabalhos para uma melhoria contínua, priorizando os itens de alto impacto (vermelhos). 
Dito isso, podemos observar a necessidade de trabalhar em cima das oportunidades: "Alterações do mercado" e também das fraquezas: "Indisponibilidade de matéria-prima para fornecer no prazo", "Perda de contrato' e "Concorrências com melhores alternativas logísticas".

Também podemos observar que o "Custo com o tratamento de madeira" atinge quatro itens em alto impacto entre oportunidades e ameaças. Outro ponto importante a ser constatado é que entre outros fatores de alto impacto como o "Atraso de embarque por dependência do fornecedor de embalagem" e "Morosidade e homem hora adicional para o fechamento do produto dentro da caixa de madeira" são fatores diretamente ligados ao modelo de madeira utilizado no processo atualmente.

\section{CONCLUSÃO}

O presente trabalho se dedicou a avaliar o uso das embalagens de madeira em processos logísticos de uma empresa do setor aeronáutico. A avaliação foi desenvolvida por meio da Análise SWOT. A análise permitiu identificar fatores relevantes sobre o uso dessas embalagens e, que de forma geral, impactam os processos logísticos da empresa, principalmente em função dos elevados custos de tratamento da madeira.

Por meio do resultado obtido neste trabalho, é admissível afirmar que o custo do tratamento da madeira é de grande impacto quando se discute sobre as fraquezas do sistema de embalagem da empresa estudada. Ao observar os fatores avaliados com alto impacto pela matriz SWOT, a concorrência com melhores alternativas logísticas também é um fator de grande preocupação para a companhia. Em entrevista com um dos supervisores do processo logístico da empresa estudada, o mesmo apontou para mudanças no processo logístico de concorrentes que passaram a utilizar alternativas às embalagens de madeira, sendo o uso de embalagens plásticas uma alternativa adotada pelas empresas do setor.

Como continuidade desse trabalho, sugere-se que sejam realizadas análises da migração das caixas de madeira para caixas plásticas, ponderando, principalmente, os custos advindos de aquisição e manutenção das mesmas.

\section{REFERÊNCIAS}

APARECIDA, A. S.; SALMONT, N. S.; ALMEIDA, V. B.; RABELO, M. H.; ABEL, J. B. A Utilização da Matriz Swot como Ferramenta Estratégica: Um Estudo de Caso em uma Escola de Idioma de São Paulo. In: VIII SIMPOSIO DE EXCELÊNCIA EM GESTÃO E TECNOLOGIA, 2011, Resende. Anais... Resende, 2011. 11f.

BAlloU, R. H. Logística Empresarial: Transportes, Administração de Materiais e Distribuição Física. $1^{\text {a }}$ ed. 22 reimp. São Paulo: Atlas, 2010.

CHIAVENATO, Idalberto. Introdução à Teoria Geral da Administração. $3^{\text {a }}$ Edição. S. Paulo: McGraw-Hill do Brasil, 2000.

CHIAVENATO, Idalberto. Planejamento Estratégico: Fundamentos e Aplicações. $1^{\text {a }}$ Edição. Rio de Janeiro: Elsevier, 2003.

CHRISTOPHER, Martin. Logística e Gerenciamento da Cadeia de Suprimentos. 4. ed. São Paulo: Cengage Learning, 2011. 


\section{ISSN 2447-5378}

COYLE, J. J.; BARDI, E. J.; LANGLEY, C. J. The management of business logistics: a supply chain perspective. $7^{\mathrm{a}}$ ed. Mason, $\mathrm{OH}$ : South-western, 2003.

DIAS, M. A. P. Administração de materiais: uma abordagem logística. 4 ed. São Paulo: Atlas, 1993.

FARIA, A.C.; COSTA, M.F.G. Gestão de Custos Logísticos. 1 ed. 5 reimp. São Paulo: Atlas, 2010.

GURGEL, FLORIANO DO AMARAL. Administração da Embalagem. São Paulo: Thomson Learning, 2007.

LEITE, Paulo Roberto. Logística Reversa: Meio Ambiente e Competitividade. São Paulo: Pearson Prentice Hall, 2009.

MATOS, J G. R.; MATOS, R. M. B.; ALMEIDA, J. R. Análise do Ambiente Corporativo: do caos organizado ao planejamento. $1^{\circ}$ Edição. Rio de Janeiro: E-papers, 2007.

MATOS, J G. R.; MATOS, R. M. B.; ALMEIDA, J. R. Análise do Ambiente Corporativo: do caos organizado ao planejamento, 2007 apud SIQUEIRA, R. S.; NASCIMENTO, M. V. A Análise SWOT como ferramenta para avaliação do posicionamento estratégico do uso de drones na logística de distribuição. 2016. 5f. Artigo 5a Jornada Científica e Tecnológica da FATEC de Botucatu- Faculdade de Tecnologia de São José dos Campos, 2016.

MESTRINER, F. Gestão estratégica de embalagem: uma ferramenta de competitividade para sua empresa. São Paulo: Pearson Prentice Hall, 2007.

MOURA, R. A.; BANZATO, J. M. Embalagem, Unitização \& Conteinerização. 2 ed. São Paulo: IMAM, 1997.

NOVAES, F. A logística Reversa das Embalagens de Caixas de Papelão e seu Impacto Ambiental. 2009.

PAOLESCHI, B. Logística Industrial Integrada - Do planejamento, Produção, Custo e Qualidade à Satisfação do Cliente. 2. ed. São Paulo: Érica, 2009.

PEDROSO, M.C.; ZWICKER, R. Sustentabilidade na cadeia reversa de suprimentos: um estudo de caso do projeto plasma. R. Administração., São Paulo, v.42, n.4, p.414-430, out./nov./dez. 2007.

PINHO, Djalma Rebouças de Oliveira. Planejamento Estratégico: Conceitos Metodologia Práticas. $21^{\text {a }}$ Edição. São Paulo: Atlas, 2004.

ROGERS, D. S.; TIBBEN-LEMBKE, R. Going Backwards: Reverse Logistics Trends and Practices. Reno: Reverse Logistics Executive Council, 1998.

SANTOS, R. F. Proposta de um modelo de gestão integrada da Cadeia de suprimentos: aplicação no segmento de eletrodomésticos. 2010. 202f. Tese de Doutorado - Instituto Tecnológico de Aeronáutica, São José dos Campos, 2010. 


\section{ISSN $2447-5378$}

TADEU, Hugo Ferreira Braga...[et al.]. Logística Reversa e Sustentabilidade. São Paulo: Cegage Learning, 2013. 